\title{
Mulheres, soropositividade e escolhas reprodutivas
}

\section{Women, seropositivity and the reproductive choices}

\author{
Ana Carolina Cunha SANT'ANNA ${ }^{1}$ \\ Eliane Maria Fleury SEIDL ${ }^{1}$ \\ Ana Lúcia GALINKIN ${ }^{1}$
}

\begin{abstract}
Resumo
0 crescimento da epidemia do vírus da imunodeficiência humana entre as mulheres vem atualizando questões referentes à sexualidade e à reprodução. Este estudo investigou a percepção de mulheres portadoras do vírus da imunodeficiência humana positivo quanto às escolhas reprodutivas no contexto da soropositividade. Optou-se pela metodologia qualitativa, com a utilização de um grupo focal com mulheres soropositivas residentes no Distrito Federal. Na análise dos resultados, observou-se que as participantes estavam bem informadas sobre o processo de prevenção da transmissão vertical. A condição sorológica teve impacto na vida sexual e reprodutiva, evidenciado no adiamento ou extinção dos planos de ter filhos. A reação das pessoas em geral, bem como do profissional de saúde, diante do desejo de ter filhos por parte da mulher soropositiva foi apontada como desfavorável. Os achados do estudo, de caráter exploratório e preliminar, apontam para a relevância da realização de pesquisas na área, a fim de que os direitos reprodutivos das mulheres soropositivas sejam compreendidos, favorecendo sua valorização e respeito.
\end{abstract}

Unitermos: Gravidez. Mulheres. Síndrome de imunodeficiência adquirida.

\begin{abstract}
Thegrowth of thehuman imunodeficiency virus epidemic among women bringsinto focusquestions of sexuality and reproduction. This study investigated the perception of women, who areseropositive, as to their reproduction choices in the context of seropositivity. Qualitativemethodology was chosen with theuse of a focusgroup comprising seropositivewomen living in theFederal District (Brasilia). On analyzing the results, it wasobserved that theparticipants werewell informed about the process of prevention of vertical transmission. Theserological condition had an impact on their sexual and reproductive life, evidenced bythepostponement or abandonment of plans to have children. The reaction of people in general, as well as the health professional, faced with the seropositive woman's desire to have children, was shown to be unfavorable. The results of this exploratory and preliminarystudy, demonstratetheimportanceof developing research studies in the area, in order to understand the rights of these seropositivewomen to reproduce, helping to accord them valueand respect.
\end{abstract}

Uniterms: Pregnancy. Human females. Acquired immunodeficiency Syndrome.

No Brasil, dados epidemiológicos indicam a manutenção das taxas de incidência do Human Immunodeficiency Virus/Síndrome da Imunodeficiência Adquirida (HIV/Aids) em patamares estáveis, totalizando 17,2 casos por 100 mil habitantes em 2004. No Distrito Federal, foram notificados 21,2 casos por 100 mil habitantes (Ministério da Saúde, 2005a).

\footnotetext{
1 Universidade de Brasília, Instituto de Psicologia. Campus Universitário Darcy Ribeiro, 70910-900, Brasília, DF, Brasil. Correspondência para/Correspondence to:A.C.C. SANT'ANNA.E-mail: <anac.santanna@gmail.com>.
} 
Embora o número de pessoas do sexo masculino ainda seja mais elevado que o do feminino, verifica-se um aumento da infecção pelo HIV entre as mulheres brasileiras (Brito, Castilho \& Szwarcwald, 2001; Rodrigues-Júnior \& Castilho, 2004). Em 1985, a cada vinte e seis casos masculinos era notificado um caso feminino, enquanto em 2004, a razão homem/mulher indica a freqüência de quinze casos de homens para cada dez mulheres infectadas pelo HIV (Ministério da Saúde, 2005a).

As taxas de incidência de Aids em mulheres, segundo a faixa etária, demonstram crescimento persistente em praticamente todas as idades, com exceção das menores de cinco anos. É relevante salientar que, dos 4952 casos do sexo feminino notificados em 2004, 81,5\% tinham entre 20 e 49 anos, ou seja, estavam em idade reprodutiva (Ministério da Saúde, 2005a). Apesar de a mortalidade por Aids no Brasil manter-se estabilizada desde 1998, os índices mostram redução menos acentuada entre as mulheres (Brito et al., 2001).

Os dados apresentados sinalizam a necessidade de um redirecionamento das políticas públicas em HIV/Aids. Como salienta Guilhem (2005), o novo panorama da Aids no país tem desnudado a condição de vulnerabilidade a que as mulheres estão expostas. As práticas em saúde, muitas vezes ainda influenciadas pelo modelo biomédico, têm dado pouca atenção aos determinantes socioculturais, morais e políticos que contribuem significativamente para este cenário.

Quando a mulher se descobre soropositiva em idade reprodutiva é confrontada, muitas vezes, com algumas decisões difíceis, dentre elas a escolha sobre ter ou não filhos. Assim, a maternidade, que em nossa cultura parece serum papel social esperado e valorizado, comumente desejado pelas mulheres, pode se tornar ameaçada pela condição sorológica (Knauth, 1999).

A transmissão vertical do HIV - da mulher gestante soropositiva para o bebê - pode ocorrer durante a gravidez, no parto ou pela amamentação. No entanto, resultados obtidos com o protocolo ACTG 076 e estudos subseqüentes possibilitaram uma diminuição relevante do risco de transmissão vertical do HIV em gestantes soropositivas (Connor et al., 1994; Newell, Gray \&Bryson, 1997; Wade, Birkhead \&Warren, 1998). Com base nessas evidências, desde 1996 o govemo brasileiro disponibiliza de profilaxia da transmissão vertical. Este procedimento tem repercutido diretamente sobre a incidência de casos de Aids em crianças, que vem decrescendo progressivamente em nosso país (Ministério da Saúde, 2004).

O impacto do diagnóstico da infecção pelo HIV na vida sexual e afetiva da mulher tem sido documentado em diversos trabalhos: Paiva, Latorre, Gravato e Lacerda (2002), após entrevistarem 1068 mulheres HIV+, verificaram que, apesar de a maior parte $(54 \%)$ relatar vida amorosa e sexual ativas, a comunicação do diagnóstico ao parceiro, a negociação do uso de preservativos e o medo de rejeição foram citad os como eventos estressores. Outro estudo verificou que, em um grupo de 148 mulheressoropositivas, menos da metade continuou mantendo vida sexual ativa, embora tivessem relatado desejo de fazer sexo (Santos et al., 2002).

0 exercício da sexualidade para as mulheres em nossa cultura parece ainda estar muito atrelado à matemidade (Giffin, 1991; Mandu, 2002).Apesar de grande parte dos estudos referir um impacto negativo da soropositividade na vida sexual das mulheres, isto parece não ocorrer com relação ao desejo de ter filhos. À guisa de exemplo, pesquisa desenvolvida por Paiva et al. (2002) verificou que, dentre aquelas mulheres que tinham parceria sexual estável, $13 \%$ desejavam ter filhos. Essa proporção foi ainda maior entre o grupo de mulheres com menos de 30 anos (39\%). Dados de outro estudo brasileiro corroboraram os resultados de Paiva et al. (2002): em amostra de 148 mulheres na faixa etária entre 19 e 63 anos, 21\% manifestaram o desejo de ser mãe (Santos et al., 2002).

Apesar de alguns estudos identificarem que a condição sorológica parece não interferir no desejo de ser mãe, outras pesquisas sugerem que a soropositividade tem impacto na realização de suas escolhas reprodutivas: investigação pioneira realizada na Austrália, no final dos anos 90, mediante 0 acesso aos registros médicos de 294 mulheres diagnosticadas com infecção pelo HIV, revelou que, dentre as gestações confirmadas após o diagnóstico de soropositividade, $47 \%$ das mulheres optaram pelo aborto, taxa que equivale a mais que o dobro da média de abortos na população em geral daquele país (Thackway et al., 1997). 
Bedimo, Bessinger e Kissinger (1998) compararam grupos de mulheres soropositivase soronegativas para o HIV com relação às suas escolhas reprodutivas. Foi constatado que mulheres HIV+ tiveram quedas nas taxas de fertilidade e elevação nas taxas de esterilização, quando comparadasàs soronegativas. Estudo brasileiro corroborou os achados de Bedimo et al. (1998), ao observar que as taxas de esterilização em mulheres soropositivas são maiores se comparadas às da população feminina em geral (Barbosa \& Knauth, 2003).

Investigação realizada em duas capitais brasileiras buscou identificar fatores condicionantes que poderiam interferir nas escolhas reprodutivas de gestantes HIV+ focalizando, em particular, o papel desempenhado pelos serviços de saúde sobre o desejo e a realização de laqueadura tubária no pós-parto. Foram acessados 427 prontuários clínicos e realizadas 60 entrevistas com mulheres HIV+. A maior parte das entrevistadas, nas duas capitais, manifestou desejo de realizar a esterilização logo após o parto (29 mulheres em Porto Alegre e 28 em São Paulo). Entretanto, a discrepância na realização de tal procedimento - 4,4\% das mulheres de Porto Alegre foram esterilizadas, ao passo que, em São Paulo, o percentual chegou a 50,6\% - sugere que a cultura médica local parece exercer papel importante sobre as opções reprodutivas das mulheres (Barbosa \& Knauth, 2003; Knauth, Barbosa, Hopinks, Pegoriano \& Fachini, 2002).

No percurso entre o desejo e a realização de suas escolhas, a mulher que vive com HIV/Aids parece encontrar, muitas vezes, acolhimento insatisfatório pela equipe de saúde. É comum o relato da pouca atenção dos serviços a estas questões (Santos et al., 2002; Diaz, Schable \& Chu, 1995). Santos et al. (2002) constataram que $12 \%$ de uma amostra de 148 mulheres HIV+ relataram sentir-se destratadas por médicos e outros profissionais de saúde ao expressarem suas vontades na esfera dos direitos reprodutivos.

Outro aspecto digno de nota refere-se ao nível de informação das mulheres HIV+ sobre contracepção e profilaxia da transmissão vertical do HIV, muitas vezes inferior ao desejável. llustram essa afirmativa os achados de estudo realizado em centros de referência em DST e Aids de São Paulo, cujos resultados indicaram que 53\% das mulheres não tinham sido informadas sobre a existência de práticas contraceptivas mais indicadas (Paiva et al., 2002).
Ainda com relação à contracepção pós-diagnóstico, um estudo quantitativo verificou que o preservativo foi o método mais comumente utilizado por mulheres HIV+. Todavia, com relação ao número de gestações após a soropositividade, houve predomínio de gravidez não planejada. Podemos supor que, apesar de mulheres soropositivas referirem o preservativo como principal método contraceptivo, seu uso parece não estar sendo consistente e eficaz na prevenção da gravidez (Lindsay et al., 1995).

Outros aspectos que merecem atenção na temática das escolhas reprodutivas são a mudança do panorama epidemiológico e a tendência de consolidação da Aids como enfermidade crônica, o que tem levado ao aumento da conjugalidade entre pessoas com sorologias diferentes para o HIV. Um grande desafio é compreender como as escolhas reprodutivas ocorrem neste contexto. De acordo com Polejack (2001), para o casal sorodiscordante a decisão sobre ter ou não ter filhos apresenta peculiaridades importantes, como a possibilidade de transmissão do HIV para o parceiro não infectado, além do risco de transmissão do vírus para o bebê, no caso de a mulher ser a pessoa infectada. Como sinalizam Polejack e Costa (2002), a partir do diagnóstico de soropositividade, os casais precisam desenvolver estratégias de enfrentamento em relação ao risco sexual, visando diminuir o stress oriundo da preocupação com uma possível contaminação do parceiro/a, ao lado do desejo de permanecerem sexualmente ativos e realizarem suas escolhas reprodutivas.

Estudo qualitativo realizado por Reis (2004) analisou o impacto da sorodiscordância na vida afetivo-sexual de portadores do HIV/Aids que conviviam com parceiro/a heterossexual soronegativo/a. Os achados sugeriram que o medo de contaminar o parceiro/a HIV negativo pode trazer implicações importantes na esfera reprodutiva e contraceptiva. Dentre os onze casais participantes, observou-se diminuição do desejo sexual aliada à desconfiança sobre a eficácia do preservativo na prevenção da infecção pelo HIV. Segundo relatos, a dificuldade de diálogo sobre o tema entre os casais parecia interferir em suas escolhas. Apesar de os motivos predominantes destacados pela autora para 0 desejo de não ter filhos estarem relacionados às dificuldades financeiras dos cônjuges- de criarem os filhos 
no mundo atual, ao lado do fato de já terem filhos -, aspectos relativos à reprodução no contexto da sorodiscordância mereceriam ter sido discutidos na esfera do casal ou dos serviços de saúde.

Outra investigação qualitativa realizada por Dalapria e Neto (2004), com seis casais heterossexuais com sorologia diferente para o HIV, descreveu suas práticas sexuais e escolhas reprodutivas. Verificou-se redução das práticas sexuais e dificuldades de negociação do uso consistente do preservativo. Dentre os casais, dois relataram desejo de ter filhos, e nenhum dos participantes referiu conhecer técnicas de reprodução assistida, que poderiam ser indicadas nestes casos.

Políticas públicas em defesa dos direitos reprodutivos de homens e mulheres brasileiros foram recentemente anunciadas pelo Governo Federal, no âmbito do Ministério da Saúde, divulgadas no documento "Direitos Sexuais e Direitos Reprodutivos: uma prioridade de governo" (Ministério da Saúde, 2005b). Dentre essas medidas, estaria o acesso a técnicas modernas de reprodução assistida em serviços públicos e gratuitos como mais uma opção para se ter filhos. Para as mulheres soro positivas ou parceiras de pessoas soropositivas - que deverão ter acesso privilegiado a esse programa - surge uma nova possibilidade, que poderá vir a legitimar seus direitos sexuais e reprodutivos.

Considerando que os comportamentos de escolha reprodutiva se modificam ao longo de uma história de vida, e são fortemente conectados às redes socioculturais nas quais os sujeitos estão inseridos, 0 presente estudo, de caráter preliminar, teve como objetivo apreender a percepção de mulheres HIV+ quanto às escolhas reprodutivasno contexto da soropositividade. Para tanto, algumas questões nortearam este estudo: as mulheres soropositivas atendidas na rede pública de saúde estão munidas de informações e conhecimentos sobre contracepção e prevenção da transmissão vertical do HIV? A soropositividade tem impacto sobre suas escolhas reprodutivas? A equipe de saúde tem acolhido estas escolhas? Considerando a natureza exploratória do estudo, não foi possível traçar expectativas de resultados quanto à temática investigada.

\section{Método}

Esta pesquisa foi submetida à apreciação do Comitê de Ética em Pesquisa da Faculdade de Ciências da Saúde da Universidade de Braślia, sendo aprovada conforme processo $n-009 / 2006.0$ estudo foi conduzido nas dependências do Projeto Com-Vivência (Ações Integradas de Estudos e Atendimento a Pessoas Portadoras de HIV/Aids e Familiares), um projeto de extensão universitária de ação contínua, desenvolvido no Hospital Universitário de Brasília (HUB), desde 1996 (Seidl \& Silva, 2002). Ações voltadas para a prevenção da transmissão vertical junto ao pré-natal do HUB e direcionadas a mulheres soropositivas gestantes vêm sendo uma das prioridades do Projeto Com-Vivência (Carvalho, Seidl, Lima \& Silva, 1999; Seidl, Carvalho \& Silva, 1999).

Trata-se de um estudo descritivo, de delineamento qualitativo. Partindo-se do pressuposto teórico de que os grupos são atores naturais de pesquisa, na medida em que constroem, desconstroem e reconstroem o significado das realidades sociais, recorremos à técnica de grupo focal para a coleta de dados. 0 que define um grupo focal, e o diferencia de outros, é o fato de ser constituído com fins de pesquisa e a discussão ser focalizada em um ou alguns temas propostos pelo pesquisador (Carlini-Cotrim, 1996).

A opção por este método esteve pautada no caráter exploratório do estudo, que não teve a pretensão de identificar visões rep resentativas da população como um todo.

\section{Participantes}

Foram convidadas a participar do grupo focal seis mulheres soropositivas residentes no Distrito Federal, a partir dos seguintes critérios de inclusão: estar em idade reprodutiva (entre 18 e 45 anos), não ter realizado laqueadura tubária e não possuir filhos.

As mulheres foram convidadas em uma organização não governamental do DF que atende pessoas soropositivas e no Projeto Com-Vivência, quando foram explicitados os objetivos do estudo, com base nas normas e princípios que regulamentam as pesquisas com seres humanos. 
Apesar de as mulheres convidadas terem confirmado a presença, inclusive na véspera da data de realização do grupo focal, apenas três compareceram no dia e horário marcados. Duas delas informaram a impossibilidade de comparecimento, por telefone, momentos antes do início do grupo, e uma não justificou os motivos de sua ausência. As idades das três participantes variaram de 30 a 35 anos. Quanto ao nível de escolaridade, uma participante tinha o Ensino Médio, outra tinha o Superior completo e a terceira tinha completado o Ensino Fundamental. As três referiram a existência de parceiro fixo, sendo uma casada e duas namoravam há mais de dois anos. Um dos parceiros era HIV + (de quem a participante havia se infectado) e dois deles eram soronegativos. Com relação ao conhecimento do parceiro sobre a sorologia da participante, uma delas ainda não havia revelado sua condição sorológica para seu parceiro soronegativo.

Quanto à condição médico-clínica, duas participantes eram assintomáticas e uma era sintomática, sendo que já havia sido internada duas vezes por problemas de saúde decorrentes da soropositividade. No período do estudo, todas as participantes estavam em boas condições de saúde. Duas faziam uso da terapia anti-retroviral (TARV) e relataram descoberta do diagnóstico há mais de cinco anos. Uma delas, assintomática e de descoberta do diagnóstico há cerca de dois anos, não tinha indicação médica para início da TARV.

No que tange às práticas sexuais seguras, todas as participantes referiram fazer uso regulare consistente do preservativo masculino. As principais justificativas para esta prática foram: medo da recontaminação e de exposição do parceiro ao vírus. Quando questionadas se utilizavam algum outro método contraceptivo, duas responderam fazer dupla proteção (uso de preservativo associado a pílula anticoncepcional).

\section{Procedimentos}

Conforme os preceitos éticos que regem as pesquisas com seres humanos (Ministério da Saúde, 1996), foi elaborado um termo de consentimento livre e esclarecido para ser apresentado às participantes, reiterando os objetivos do estudo, duração estimada do grupo e convidando-as a participar. 0 sigilo quanto às informações prestadas, bem como a voluntariedade, foram explicitados. A gravação em áudio do grupo focal foi efetuada após autorização das participantes, que assinaram o termo em duas vias.

Inicialmente as mulheres preencheram um questionário com perguntas abertas e fechadas que continham informações sociodemográficas, tempo de conhecimento do diagnóstico, uso de medicação anti-retroviral, uso de preservativo e métodos contraceptivos, e tipo de parceria sexual.

0 grupo foi conduzido por duas pesquisadoras, previamente treinadas, a partir de um rotei ro pré-estabelecido que continha questões referentes ao nível de conhecimento e informações sobre transmissão vertical do HIV, profilaxia e riscos; percepção sobre a reação social das pessoas em geral e da equipe de saúde quanto ao direito reprodutivo da mulher soropositiva; impacto da soropositividade sobre as escolhas reprodutivas e, por fim, expectativas relacionadas ao papel da equipe na promoção da saúde sexual e reprodutiva de mulheres que vivem com HIV/Aids.

Após o encerramento do grupo focal, que teve duração de uma hora e quarenta e cinco minutos, foi distribuído material educativo, contendo informações sobre prevenção da transmissão vertical do HIV e planejamento familiar.

Por se tratar de uma abordagem qualitativa, os dados colhidos foram interpretados a partir das falas das participantes, por meio de análise de conteúdo, definida por Bardin (2004) como "um conjunto de técnicas de análise das comunicações visando obter, por procedimentos sistemáticos e objetivos de descrição de conteúdo das mensagens, indicadores- quantitativos ou não - que permitam a inferência de conhecimentos relativos às condições de produção/recepção (variáveis inferidas) destas mensagens". Como sinaliza Minayo (2000), este tem sido o método mais comumente adotado no tratamento de pesquisas qualitativas.

Os relatos, citados no texto entre aspas, são emblemáticos das temáticas encontradas, nem sempre as mais representativas, mas mesmo assim significativas para a compreensão da diversidade da experiência das mulheres que compuseram o grupo estudado. 


\section{Resultados}

Na análise dos relatos verbais, foi verificado que as participantes, de modo geral, estavam bem informadas sobre todas as etapas do processo da transmissão vertical, englobando o protocolo de profilaxia, bem como o percentual de risco de infecção pelo HIV do bebê. Dentre todas as etapas, o momento do parto foi 0 maior gerador de dúvidas entre as participantes:

Informação que eu sei é que a mãe tem que tomar a medicação na hora do parto. Maseu ainda tenho muita dúvida na hora do nascimento, porqueeu sei queo bebê tem quetomaroAZT, masna hora denascer, como éque vai serna hora decortaro umbigo, porqueeu acho quea transmissão émesmo naquela hora, na hora de cortaro umbigo....

Entretanto, 0 fato de a mulher HIV+ não poder amamentar foi citado como a etapa mais difícil de ser aceita, dentre o conjunto de procedimentos para a prevenção da transmissão materno-infantil: "Nós não podemosamamentarnosso bebê.... Adorémuita, a gente atéseemociona quandoa gentefala, edói... dói... Mastudo bem. Desdequeelevenha com saúde...."

A pressão social referente ao aleitamento materno foi percebida de modo negativo entre as mulheres estudadas: segundo os relatos, o fato de não amamentar poderia, por um lado, denunciar a condição so rológica da mulher e, por outro, representaro não cumprimento de um papel social esperado. "Uma amiga da genteque teve neném, ela tem o bico do peito que racha, então ela não teve problemas. Quando alguém perguntar, a gente vai falar isso também".

Nessa perspectiva, a medicação prescrita para a mulher logo após o nascimento do bebê, visando a inibição da produção do leite materno, foi mencionada como importante aliada da mulher soropositiva, tendo em vista a meta do não aleitamento: "E o bom desse remédio équea gentenem vai ver esseleite, então a dorvai serbem menor,écomo se 'eu não dei leite', não amamentei porqueeu não produzi".

A condição sorológica teve impacto na escolha reprodutiva das participantes, evidenciada no adiamento ou mesmo extinção dos planos com relação a ter ou não filhos. Dentre elas, duas ainda pensam em ser mães, enquanto uma relatou que a condição sorológica a fez desistir da maternidade:
Eunão quero ter. Realmentenão. Porqueeu penso assim: pra mim nãoadianta terum filho enão podercuidardele. Hojeeu tô bem, eamanhã? Como équevai ser? Edaqui a cinco anos, edaquia dezanos? Anteseutinha vontade. Masagora eu não tenho mais.

Dentre as que revelaram a intenção de ser mãe, duas relataram que a soropositividade retard ou o plano:

Ser soropositiva atrapalha muito o 'sermãe' ... . Sea gente retardou até agora pra fazer tudo muito certo, agora a gente vem retardando um pouco mais o ser mãe.... Se não fosse o vírus, aconteceria (referindo-seà gravidez).

Acho quea precaução aumentou. Eu sempre desejei ser mãe, mas sempre tive aquela precaução: 'não agora'. Quero ter uma casa, ter condições de levar meu filho na escola, dar uma boa escola, uma boa educação. Ehoje eu não penso maissó nisso. Penso num bom convênio de saúde. ... Eu quero ter meu filho, mas com responsabilidade.

De acordo com os relatos identificados, a atitude das pessoas diante do desejo de maternidade de uma mulher soropositiva é percebida, geralmente, como desfavorável. A falta de informação sobre a prevenção da transmissão vertical, ao lado do preconceito ainda existente, foram os principais argumentos levantados pelas participantes. Foi assinalado que a maternidade, no contexto da soropositividade, ainda é vista pela população em geral como um ato de irresponsabilidade e egoísmo: "Em relação a ser mãe, eu vou falaro quea mãe da minha amiga, queésoropositiva, falou: 'vocêédoida. Vocêtá pensando quevocênão tem HIV'?".

As participantes apontaram que a mídia poderia contribuir substancialmente para a diminuição do preconceito e agir em defesa dos direitos reprodutivos das pessoas soropositivas. Outro aspecto enfocado foi o despreparo de líderes religiosos ao tratar a questão da soropositividade, vista ainda de modo estigmatizado e pouco acolhedor: apesar de a maioria das participantes professarem alguma religião, nenhuma havia revelado seu diagnóstico no grupo religioso que freqüentava.

Quando questionadas sobre como achavam que seus médicos reagiriam à escolha de se tornarem mães, a reação esperada por elas era de apoio e acolhimento à decisão tomada. Uma das participantes informou que já havia relatado a sua intenção, e que foi apoiada pelo profissional que a acompanha: "Eu vou falar do meu médico: primeiro eu achei queeleia achar ruim, masnão, 
eledisse: 'tá, vocêvai ser mãe'. Elenão tirou meu sonho. Tá meincentivando".

Entretanto, as experiências de outras mulheres $\mathrm{HIV}+$ de seus círculos de relacionamentos, relatadas pelas participantes, permitem concluir que nem todos os profissionais parecem estar preparados, técnica e emocionalmente, para atender a essa demanda. Foi mencionado por elas que alguns tendem a encaminhar para outros profissionais, supostamente mais capacitados para atendê-las, enquanto outros se recusam até mesmo a prestar atendimento:"Ela perdeu o filho porque o médico não quisfazer o parto. Tava no dia, ela passando mal, e ele: 'Não vou fazer o parto'. Ele (o bebê) morreu. 0 médico não tirou. Então assim, tem muitosmédicosainda irresponsáveis".

A falta de capacitação específica dos profissionais de saúde sobre o tema em foco foi apontada como uma falha ainda muito comum. De acordo com o relato do grupo, o preconceito em relação às pessoas que vivem com o HIV/Aids persiste também entre os profissionais de saúde: a primeira pergunta da fichinha do médico ésempre:'vocêtoma alguma medicação?' Tomo'. Aí, olham esperando quea gentediga: 'ah, eu sou diabética', equando a gentefala:'eu sou soropositiva'a gentejá vê: ou elequermuito 'darcolo'pra gente, ou afasta logo a cadeira.

Atitudes preconceituosas também foram referidas pelas participantes entre alguns profissionais que atuam diretamente em serviços de referência em DST e Aids:

“Tem um médico lá (do Centro de Referência em HIV/Aids) queémuito bom, mascom os pacientes dele écruel.Jácanseidevercomo équechega lá ediz:'vocêvai morrer'. Um profissional? Tem muito problema com relação a isso. Defalar o queéo HIV,Aids, de explicar pra gente".

A qualificação das equipes de saúde foi citada por todas as mulheres como um caminho para uma atenção integral, em prol dos direitos da pessoa soropositiva, dentre eles, o direito reprodutivo. Outro aspecto abordado foi a respeito da luta por uma legislação específica que acolha o aborto como uma opção para mulheres soropositivas que não queiram levar uma gestação a termo:

Eu vejo duas formas pra respeitarem nossos direitos: a qualificação de quem atendea genteeem forma delei. Profissionaisprópriosda área, pra ajudara gentea tomar atitude, quando a mulher diz 'eu quero ter um filho' edar toda a assistência possível. E lei no caso das que não querem ter filho eter direito ao aborto, seja legalizado pra pessoas portadoras. Eu acho que isso deveria ser lei. Ter todo o procedimento pra quem quer e quem não quer ter.

\section{Discussão}

Os achados do presente estudo, de caráter exploratório e preliminar, apontam para a relevância da realização de pesquisas na área a fim de que os direitos reprodutivos das mulheres soropositivas sejam compreendidos, favorecendo sua valorização e respeito. A opção pelo uso de metodologia qualitativa, mediante a realização de grupo focal, foi condizente com os objetivos propostos. Entretanto, a ausência de metade das mulheres previamente confirmadas chama a atenção para que haja um maior cuidado na etapa de recrutamento de participantes para esse tipo de atividade. Sugere-se convidar um número cerca de $30 \%$ a $50 \%$ maior de pessoas do que aquele que seria necessário para a condução do grupo, no sentido de se prevenir contra ausências inesperadas.

Apesar do número limitado de participantes, foi possível ter acesso a informações relevantes sem comprometer o alcance dos objetivos do estudo. A caractenização sociodemográfica do grupo foi bastante diversificada. 0 nível de escolaridade, por exemplo, variou do Ensino Fundamental ao Superior completos, o que permitiu o acesso à opinião de mulheres com situações distintas nessa dimensão. Em contraposição aos estudos de Paiva et al. (2002), as participantes ap resentaram bom nível de informação sobre transmissão vertical do HIV, profilaxia e riscos, independentemente do número de anos de estudo de cada uma delas.

Corroborando os achados de Santos et al. (2002), a predominância de casais sorodiscordantes entre as participantes sugere alguns desafios, tais como informar a condição sorológica ao parceiro e negociar o uso consistente da camisinha nas relações sexuais. Para aquelas que ain da desejem ser mães, a sorologia discordante implica em questões mais complexas, em que a possibilidade de ter filhos pode significar a exposição do parceiro ao vírus (Dalapria \& Neto, 2004; Polejack, 2001; Polejack \& Costa, 2002; Reis, 2004). Nesses casos, 0 
desenvolvimento de uma política pública na área da reprodução assistida é fundamental, com o propósito de garantir o direito à maternidade e à paternidade de pessoas que vivem e convivem com o HIV/Aids.

Os relatos das participantes sugerem que a manutenção da atividade reprodutiva é uma importante estratégia utilizada pelas mesmas para fazer face a dificuldades sociais, culturais e psicológicas acarretadas pela Aids. Entretanto, como indicam alguns estudos acessados, o impacto negativo da condição sorológica pode estar interferindo nas escolhas reprodutivas destas mulheres (Barbosa \& Knauth, 2003; Bedimo et al., 1998; Knauth et al., 2002).

Aspectos relacionados à contracepção merecem ser melhor abordados nos serviços de saúde. Dentre as participantes, nem todas faziam uso de dupla proteção (uso de preservativo associado a outro método contraceptivo), tal como foi verificado em pesquisa desenvolvida por Lindsay et al. (1995). Considera-se fundamental que métodos complementares sejam orientados e discutidos nos programas de atendimento a mulheres que vivem com HIV/Aids, para que haja um planejamento familiar efetivo. Em paralelo, deve-se discutir 0 acesso das mulheres soropositivas ao aborto como mais uma opção no campo dos direitos reprodutivos.

As campanhas de incentivo ao aleitamento, muito difundidas no Brasil nas últimas décadas, que enfatizam os benefícios da amamentação para a saúde da mulher e da criança, parecem ter um impacto negativo sobre as mulheres pesquisadas, já que estas mencionaram se sentir, muitas vezes, em conflito por não poderem prover seus filhos com o leite materno. Há indícios de que o não aleitamento pode acarretar sofrimento psicológico para a mãe soropositiva, indo ao encontro de resultados obtidos em estudo qualitativo desenvolvido com seis mulheres HIV+ que tiveram filhos e fizeram o protocolo de prevenção da transmissão vertical (Oliveira, Guércio \& Seidl, 2003). As autoras constataram que a metade das participantes relatou desejo e sentiu falta de amamentar seus filhos, não obstante todas terem referido o não aleitamento e a utilização de fórmulas lácteas artificiais como alimento substituto ao leite materno. Outra fonte de preocupação para as mulheres HIV+ grávidas ou puérperas refere-se ao fato de a não amamentação levantar suspeitas sobre o seu status sorológico, expondo-as eventualmente à estigmatização social.

Faz-se necessário, portanto, compreender as circunstâncias complexas nas quais essas decisões são tomadas e apoiadas - ou não - pelas equipes de saúde, o que implica em focalizar não apenas as características e desejos individuais das mulheres HIV+, mas também as práticas dos profissionais e dos serviços de saúde.

Assim, os resultados desse trabalho apontam a importância de se compreender melhor as escolhas reprodutivas das mulheres no contexto do HIV/Aids, considerando outros aspectos além do componente individual. Destaca-se ainda que os objetivos que motivaram e nortearam o presente estudo foram alcançados, na medida em que serviu de base para 0 planejamento de uma pesquisa mais ampla, que contemple um número maior de participantes e questões relevantes que não foram abordadas neste estudo preliminar.

\section{Referências}

Barbosa, R. M., \& Knauth, D. R. (2003). Esterilização feminina, AIDS e cultura médica: os casos de São Paulo e Porto Alegre, Brasil. Cadernos deSaúdePública, 19(2), 365-376.

Bardin, L. (2004). Análise de conteúdo. Lisboa: Edições 70.

Bedimo, A. L., Bessinger, R., \& Kissinger, P. (1998). Reproductive choices among HIV positive women.Social Science and Medicine, 46 (2), 171-179.

Brito, A. M., Castilho, E. A., \& Szwarcwald, C. L. (2001). AIDS e infecção pelo HIV no Brasil: uma epidemia multifacetada. Revista da SociedadeBrasileira deMedicina Tropical, 34 (2), 207-217.

Carlini-Cotrim, B. (1996). Potencialidades da técnica qualitativa grupo focal em investigações sobre abuso de substâncias. Revista de Saúde Pública, 30 (3), 285-293.

Carvalho, W. E. S., Seidl, E. M. F., Lima, L., \& Silva, L. (1999). AIDS e gestação: aspectos psicossociais [Resumo]. Anais do Congresso Latino-americano de Doenças Sexualmente Transmissíveis, Salvador, 12, 116.

Connor, E. M., Sperling, R. S., Gelber, R., Kiselev, P., Scott, G., O'Sullivan, M. J., VanDyke, R., Bey, M., Shearer, W.,J Jacboson, R. L., Jimenez, E., O'Neil, E., Bazin, B., Delfraissy, J. F., Culnane, M., Coombs, R., Elkins, M., Moye, J.,Stratton, P., \& Balsey, J. (1994). Reduction of maternal infant transmission of human immunodeficiency virus type 1 with zidovudine treatment. New England J ournal of Medicine, 331, 1173-1180.

Dalapria, T. R., \& Neto, F. R. G. X. (2004). Práticas sexuais e escolhas reprodutivas de casais sorodiferentes para 0 HIV.J omal Brasileiro deDoençasSexualmenteTransmissíveis, 16 (4), 19-26. 
Diaz, T., Schable, B., \& Chu, S. (1995). Relationship betwen use of condoms and other forms of contraception among human immunodeficiency virus-infected women. Obstetrics and Ginegology, 86(2), 277-282.

Giffin, K. M. (1991). Nosso corpo nos pertence: a dialética do biológico e do social. Cadernos de Saúde Pública, 7 (2), 190-200.

Guilhem, D. (2005). Escravas do risco: bioética, mulhereseAids. Brasília: Editora UnB.

Knauth, D. R. (1999). Subjetividade Feminina e soropositividade. In R. M. Barbosa \& R. Parker (Orgs.), Sexualidades pelo avesso (pp.121-136). São Paulo: Editora 34.

Knauth, D. R., Barbosa, R. M., Hopinks, K., Pegoriano, M., \& Fachini, R. (2002). Cultura médica e decisões reprodutivas entre mulheres infectadas pelo vírus da AIDS. Interface: Comunicação, Saúde e Educação, 6(11), 39-54.

Lindsay, M. K., Grant, J., Peterson, H. B., Willis, S., Nelson, P., \& Klein, L. (1995). The impact of knowlege of human immunodeficiency virus serostatus on contraceptive choice and repetead pregnancy. Obstetrics and Gynecology, 85(5), 675-679.

Mandu, E. N. T. (2002). Trajetória assistencial no âmbito da saúde reprodutiva e sexual - Brasil, século XX. Revista Latino-Americana de Enfermagem, 10 (3), 358-371.

Minayo, M. C. S. (2000). 0 desafio do conhecimento: pesquisa qualitativa em saúde. São Paulo: Hucitec.

Ministério da Saúde. Brasil. (1996). Resolução 196/96 sobre pesquisa envolven do sereshumanos. Braślila: Ministério da Saúde.

Ministério da Saúde. Brasil. (2004). Recomendações para a profilaxia da transmissão vertical do HIVeterapia antiretroviral em gestantes. Brasília: Ministério da Saúde.

Ministério daSaúde. Brasil. (2005a). Boletim epidemiológico AIDS e DST ano II n 1 - 1a à 26a semanas epidemiológicas janeiro a junho de 2005. Brasília: Ministério da Saúde.

Ministério daSaúde. Brasil. (2005b). Ministério da Saúdelança política nacional que amplia acesso ao planejamento familiar. Recuperado em janeiro 16, 2006, disponível em www.saude.gov.br/portal/plicacoes/noticias/ noticias_detalhe.cfm?co_seq_noticia $=13728$

Newell, M-L., Gray, G., \& Bryson, Y. J. (1997). Prevention of mother-to-child transmission of HIV-1 transmission.AIDS, 11 (Supl), 1165 -1172.

Oliveira, M. J., Guércio, C. R., \& Seidl, E. M. F. (2003). Consentimento livre e esclarecido de mulheres soropositivas no uso de leites adaptados: reflexões à luz da bioética. In N. Giraldi, V. Garrafa, J. E. Siqueira \& L. Prota (Orgs.), Bioética: estudose reflexões 4 (pp.225-252). Londrina: Edições Cefil.

Paiva, V., Latorre, M. R., Gravato, N., \& Lacerda, R. (2002). Sexualidade de mulheres vivendo com HIV/AIDS em São Paulo. Cadernos de Saúde Pública, 18(6), 1609-1620.

Polejack, L. (2001). Convivendo com a diferença: dinâmica relacional decasaissorodiscordantespara o HIV.Dissertação de mestrado não-publicada, Instituto de Psicologia, Universidade de Brasília.

Polejack, L., \& Costa, L. F. (2002). Aids e conjugalidade: 0 desafio de com (viver). Impulso, Revista deCiências Sociais e Humanas, 13(1), 131-139.

Reis, R. K. (2004). Convivendo com a diferença: 0 impacto da sorodiscordância na vida afetivo-sexual de portadores do HIV/Aids Dissertação de mestrado não-publicada, Universidade de São Paulo, Ribeirão Preto.

Rodrigues-J únior, A. L., \& Castilho, E. A. (2004). A epidemia de AIDS no Brasil, 1991-2000: descrição espaço-temporal. Revista da SociedadeBrasileira de Medicina Tropical, 37 (4), 312-317.

Santos, N. J., Buchalla, C. M., Ventura-Filipe, E., Bugamelli, L., Garcia, S., \& Paiva, V. (2002). Mulheres HIV positivas, reprodução e sexualidade. Revista de Saúde Pública, 36 (4), 12-23.

Seidl, E. M. F., Carvalho, W. E. S., \& Silva, M. A. (1999). Prevenção da transmissão vertical do vírus HIV:o trabalho com gestantes em serviço de pré-natal. Anais do Congresso Latinoamericano de Doenças Sexualmente Transmissíveis, Salvador, 12, 117.

Seidl, E. M. F., \& Silva, M. A. (2002). Integrando assistência, pesquisa e ensino na atenção a pessoas vivendo com HIV/Aids: a experiência do Projeto Com-Vivência. [Resumo]. Anais do Congresso Brasileiro de Extensão Universitária, João Pessoa, 1, 296-297.

Thackway, S. V., Furner, V., Mijch, A., Cooper, D. A., Holland, D., Martinez, P., Shaw, D., Beek, I. V., Wright, E., Clesy, K., \& Kaldor, J. M. (1997). Fertility and reproductive choice in women with HIV-1 infection. AIDS, 11 (5), 663-667.

Wade, N. A., Birkhead, G. S., \& Warren, B. L. (1998). Abbreviated regimens of zidovudine prophylaxis and perinatal transmission of the human immunodeficiency virus. New England Journal of Medicine, 339 (20), 1409-1414.

Recebido em: 2/8/2006

Versão final reapresentada em: $21 / 11 / 2006$

Aprovado em:27/2/2007 
